\title{
Entre el extractivismo y el Vivir Bien: experiencias y desafíos desde Bolivia
}

\section{Fernanda Wanderley*}

Resumen. Bolivia, Ecuador y Venezuela han destacado en el mundo al proponer un nuevo paradigma de desarrollo que pretende recuperar y fortalecer la gobernanza comunitaria y los principios pluralistas de organización política: Vivir Bien, Buen Vivir y socialismo del siglo XXI. Varias interrogantes surgen de la experiencia de los gobiernos progresistas en América Latina a comienzos de los 2000. Los gobiernos que lograron canalizar una potente energía política de la sociedad, favorable a modelos alternativos de desarrollo, se apartaron en la práctica de ese compromiso: adoptaron cambios discursivos y dieron continuidad a la política económica, lo que provocó tensiones sociales y contradicciones políticas. El objetivo de este artículo es reconstruir la experiencia boliviana después de diez años de gobierno del Movimiento al Socialismo (MAS). Al respecto, se analizan las movilizaciones sociales que posibilitaron que Evo Morales asumiera la presidencia en 2006. Asimismo, se discuten los resultados del modelo de desarrollo, los cambios políticos y la fragmentación de los movimientos sociales. La comparación de la experiencia boliviana con otros gobiernos progresistas permite delinear las principales contradicciones y proyectar los desafíos de nuevos proyectos políticos progresistas en la región.

Palabras clave: Vivir Bien, movimientos sociales, gobierno progresista, extractivismo, Bolivia.

* Subdirectora de Investigación del Postgrado en Ciencias del Desarrollo de la Universidad Mayor de San Andrés, La Paz, Bolivia. 


\section{Between extractivism and Vivir Bien: experiences \& challenges from Bolivia}

Abstract. Bolivia, Ecuador and Venezuela are notable in the world for their proposal of a new development paradigm that intends to recover and strengthen grassroots government and the pluralist principals of political organization: $\mathrm{Vi}$ vir Bien, Buen Vivir and socialism of the 21st Century. Several questions arise from the experience of progressive governments in Latin America beginning in the 2000s. Those governments that succeeded in channeling a strong political energy from society, predisposed to alternative development models, nonetheless departed in practice from that commitment: they adopted controversial changes and continued the existing economic policy, provoking social tensions and policy contradictions. The objective of this article is to reconstruct the Bolivian experience after ten years of the Movement Toward Socialism (MAS) government. To that end, it analyzes the social movements that made possible Evo Morales' rise to the Presidency in 2006. It also discusses the results of the development model, policy changes and the fragmentation of social movements. The comparison of the Bolivian experience with other progressive governments allows for the identification of the key contradictions and to map out the challenges for other progressive political projects in the region.

Keywords: Vivir Bien, social movements, progressive government, extractivism, Bolivia. 


\section{Introducción}

En la década de 1990, frente al retroceso de los derechos sociales y el incremento de la pobreza, la desigualdad y los desequilibrios ambientales, viejos y nuevos movimientos de resistencia al modelo de mercado libre y autorregulado y sus desastrosas consecuencias para la reproducción de la humanidad, la naturaleza y el propio sistema económico se fueron articulando. A los movimientos antiglobalización neoliberal, de defensa del medio ambiente, de la economía social y solidaria, se sumaron los movimientos feministas, indígenas y de jóvenes que debutaron décadas antes. El manifiesto de la convivialidad, la propuesta política de otra economía, las experiencias de comercio justo, de economías de proximidad y de los cortocircuitos y solidarios son algunas de las expresiones de reclamo por una institucionalidad alternativa de organización de la economía.

$\mathrm{Al}$ interior de contextos con crecientes conflictos sociales en América Latina, ascendieron al poder partidos de izquierda en Venezuela, Brasil, Argentina, Ecuador y Bolivia en los albores del siglo XXI. Nuevas constituciones, normativas y planes de gobierno fueron aprobados señalando cambios importantes en la orientación política de la economía. La excepcional bonanza económica en la región entre 2005-2013 y la legitimidad política sostenida en gran medida a causa de la disminución de la pobreza en el corto plazo explican la continuidad de estos gobiernos por más de una década. Con el fin de la bonanza los avances sociales están en riesgo. Según el último informe del Programa de las Naciones Unidas para el Desarrollo (PNUD, 2016), entre 25 y 30 millones de personas pueden recaer en la pobreza.

Bolivia, Ecuador y Venezuela destacaron en el panorama internacional, como países que proponían un nuevo paradigma de desarrollo —el 
Vivir Bien, el Buen Vivir y el Socialismo del siglo XXI— a través de propuestas de recuperación y fortalecimiento de gobernanzas comunitarias y principios pluralistas de organización política. A nivel económico, los nuevos gobiernos se declararon promotores de un modelo económico alternativo con inclusión social y en armonía con la naturaleza. A nivel sociocultural, la opinión pública vinculó estas experiencias a la afirmación y proyección de creencias, cosmovisiones, estilos de vida y principios éticos y estéticos propios de las culturas indígenas andino-amazónicas.

En Bolivia, varias normativas fueron aprobadas para impulsar el principio constitucional de economía plural bajo el nuevo paradigma del Vivir

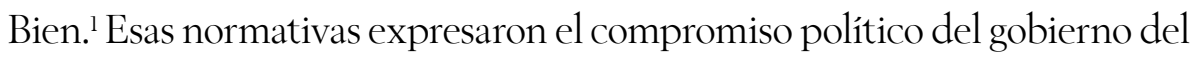
Movimiento al Socialismo (MAS) con las movilizaciones sociales que demandaron un nuevo modelo de desarrollo inclusivo, plural y en armonía con la naturaleza. Si bien la legitimidad del «proceso de cambio» se ha sostenido sobre el compromiso político de superación del modelo neoliberal y de fundación de un Estado poscolonial, las políticas y acciones estatales de los últimos diez años no siguieron una trayectoria coherente en relación con los discursos oficiales, la nueva carta magna y las normativas aprobadas. Proceso que desencadenó nuevas dinámicas políticas, sociales y económicas con la emergencia de disputas al interior de los movimientos sociales.

\footnotetext{
${ }^{1}$ Entre las normativas resaltan el Plan Nacional de Desarrollo «Para el Vivir Bien» de 2006, el Plan Sectorial de Desarrollo Productivo con Empleo Digno de 2009 y la Estrategia Plurinacional de Economía Solidaria y Comercio Justo de 2010. Importantes leyes fueron aprobadas: la Ley Marco de Autonomías y Descentralización en 2010, la Ley de la Revolución Productiva Comunitaria Agropecuaria en 2011 y la Ley Marco de la Madre Tierra y Desarrollo Integral para Vivir Bien en 2012, la Ley de Promoción y Desarrollo Artesanal de 2012, la Ley de Organizaciones Económicas Campesinas, Indígenas Originarias (Oeca) y de Organizaciones Económicas Comunitarias (Oecom) para la integración de la agricultura familiar sustentable y la soberanía alimentaria de 2013 y la Ley General de Cooperativas de 2013.
} 
Un conjunto de preguntas surge de la experiencia de los gobiernos progresistas en América Latina al inicio del siglo XXI. Es indispensable explicar las razones por las cuales los gobiernos que lograron canalizar una potente energía política gestada al interior de las sociedades a favor de modelos alternativos de desarrollo se apartaron en la práctica de esos compromisos políticos y se caracterizaron por tensiones y contradicciones entre cambios discursivos profundos y continuidades en la orientación de las políticas económicas.

El objetivo del presente texto es reconstruir la experiencia boliviana después de diez años del gobierno del MAS. Se pretende iluminar la trayectoria de las movilizaciones sociales que generaron la energía política por otra economía y otro desarrollo y que más tarde fue canalizada mediante el partido del presidente Evo Morales, quien llegó al poder en 2006. Sobre esta base se examina el modelo de desarrollo efectivamente implementado en Bolivia y sus resultados, además se discute la inflexión del proceso de cambio y la fragmentación de los movimientos sociales. Comparar el caso boliviano con las experiencias de los países con gobiernos progresistas en ese periodo permite delinear las principales contradicciones y proyectar los desafíos de nuevos proyectos políticos progresistas en la región.

\section{Los movimientos sociales en Bolivia y la propuesta política de otra economía}

Comprender la energía política que demandó otro modelo de desarrollo exige reconstruir la trayectoria de las organizaciones de la sociedad civil en el país. Bolivia se caracteriza por sólidos tejidos comunitarios y asociativos 
con formas plurales de organización social, política y económica. Una de estas formas es el gobierno comunal (no estatal) en el área rural, a través del cual campesinos e indígenas regulan sus relaciones sociales al interior de las comunidades territoriales e interaccionan colectivamente con el Estado a nivel municipal, departamental y nacional.

Además de la afiliación política a gobiernos territoriales, los indígenas y campesinos son miembros de organizaciones económicas como gremios, cooperativas, asociaciones de productores y comerciantes, unidades económicas familiares y comunidades agrarias; en ocasiones participan en más de una. Durante el siglo XX y principios del XXI, estas organizaciones económicas convivieron o se articularon con emprendimientos capitalistas, de modo que tejieron un proceso de modernización en que predominó el trabajo autogenerado. La densidad organizativa de la sociedad boliviana, sus dimensiones político-territorial y económica-ocupacional, fue y sigue siendo continuamente redefinida en los ámbitos político y simbólico por medio de disputas y rearticulaciones entre las organizaciones sociales de base, sus entes matrices y los gobiernos de turno.

A partir de 1980 emergió una nueva identidad colectiva nacional-indígena alrededor de la cual las organizaciones sociales rurales y urbanas se reconstruyeron con fundamento en la recuperación de la memoria y prácticas indígenas y originarias, hecho que sustituyó los referentes clasistas imperantes tiempo atrás. Este proceso se apoyó en la recuperación documental y académica de las prácticas e instituciones económicas de las comunidades indígenas (el ayllu), y su amplia difusión a través de centros de investigación, de acción y de radios comunitarias en idiomas autóctonos. ${ }^{2}$

${ }^{2}$ Así, instituciones comunitarias como la chunca (clasificación de equipos para el laboreo de la tierra), la mitta (turno obligatorio de trabajos agrícolas y de otro orden), la minca y el ayni 
Un sobresaliente hito en tal proceso de reconfiguración de los movimientos sociales en torno a la etnicidad fue la Marcha por el Territorio y Dignidad protagonizada por las organizaciones indígenas de las tierras bajas, lideradas por la Confederación de Pueblos Indígenas del Oriente Boliviano (Cidob) en 1990. La trascendencia de la marcha para la sociedad se revela en los cambios legales y medidas políticas de los siguientes gobiernos a favor del reconocimiento de los territorios indígenas, entre otros derechos colectivos.

A comienzos de los 1990 y a consecuencia de esa movilización, Bolivia ratificó el Convenio 169 de la Organización Internacional del Trabajo (OIT) sobre el derecho de los pueblos indígenas y aprobó decretos supremos mediante los cuales reconoció legalmente cuatro territorios indígenas: Territorio Indígena del Parque Nacional Isiboro Sécure (TIPNIS), Territorio Indígena Multiétnico Chimanes (TIMCH), Territorio Indígena del pueblo Sirionó en el Ibiato y un área de 30 mil hectáreas en el Monte San Pablo. Estos decretos también declararon la intención de promulgar una ley específica para pueblos y comunidades nativas, que más adelante se conocerá como Proyecto de Ley para los Pueblos Indígenas del Oriente, Chaco y Amazonía.

(préstamos de trabajo en beneficio general o privado), el departir (arreglo relacionado con el cultivo de tierras y que se lo hace generalmente entre un campesino que posee una yunta y poco terreno y otro que tiene mucho terreno y le faltan yuntas), el waki (arreglo que tiene tres variedades y cuyo control se realiza sobre todo en la cosecha recogiendo surcos saltados), la sattakha (que consiste en apartar un surco al borde de la legua-kallpa o pequeña parcela, para el usufructo de determinadas personas) y la kala (intercambio de leguas-kallpas entre los comunarios, con el objeto de conseguir lotes de tierra más próximos a sus casas y por lo tanto más facilidad para cultivarlos) fueron visibilizadas en una serie de documentos (Moller, 1986; Albó, 1999; Rivera, 1992; Condori, 2003). Estas instituciones remiten a los principios de solidaridad de esfuerzos, de cooperación entre familias que componen una comunidad, de trabajo colectivo de la tierra y de unidad de regulación territorial. 
La Constitución Política del Estado (CPE) de 1994 reconoció el carácter multicultural y pluriétnico de la nación boliviana. En los años siguientes se aprobaron nuevas leyes: reforma educativa intercultural bilingüe, sobre reestructuración del Estado que promovieron la integración político-administrativa de las comunidades campesinas e indígenas mediante la municipalización del país, mecanismos de participación popular y control social, establecimiento de espacios colectivos étnicos, como las Tierras Comunitarias de Origen (TCO), y respecto al medio ambiente. Estas reformas legislativas y político-administrativas progresistas fueron promovidas, paradójicamente, bajo la hegemonía de las políticas económicas neoliberales.

Los ajustes estructurales, las privatizaciones, el retroceso del frágil Estado benefactor y la precarización del empleo en el periodo neoliberal constituyeron la base material para la pérdida de legitimidad de los gobiernos de ese periodo y la convergencia de los movimientos alrededor de una agenda política común. Dicha energía social adquirió un nuevo impulso político a partir de 2000, cuando las organizaciones sociales se movilizaron por la defensa de recursos territoriales de gestión comunitaria y por el control de bienes (tierra, agua e hidrocarburos).

Se densificaron las articulaciones entre organizaciones emergentes, Coordinadora del Agua y la Vida; así como antiguas organizaciones de base territorial, Confederación de Pueblos Indígenas del Oriente Boliviano (Cidob), Consejo Nacional de Ayllus y Markas del Qullasuyo (Conamaq), Confederación Sindical Única de Trabajadores Campesinos de Bolivia (CSUTCB), Confederación Sindical de Colonizadores de Bolivia (CSCB), Federación Nacional de Mujeres Campesinas de Bolivia «Bartolina Sisa» (FNMCB-BS), Coordinadora de las Seis Federaciones del Trópico de Cochabamba (Coca Trópico) y Federación de Juntas Vecinales (Fejuve) en las 
ciudades. Dichas organizaciones conformarían el reciente núcleo del movimiento social.

Una de las demandas centrales era la apertura de una Asamblea Constituyente para la refundación del Estado y de su economía, cimentada en los principios y valores colectivos de las comunidades indígenas y campesinas. Las organizaciones sindicales de base territorial, citadas con anterioridad, y otras organizaciones populares formaron el Pacto de Unidad ${ }^{3}$ entrado el siglo XX. Éste apoyó el MAS a la vez que atestiguó la capacidad del partido para canalizar políticamente la representación de las organizaciones sociales populares de larga tradición comunitaria-indígena y sindical-cooperativista, en articulación con nuevos actores en contra de la hegemonía neoliberal, el imperialismo y el colonialismo interno.

\section{Modelo de desarrollo entre 2006 y 2016}

En el marco de los compromisos políticos con las organizaciones sociales, el nuevo gobierno del MAS lideró la instauración de la Asamblea Constituyente, en agosto de 2006, con la amplia participación de los actores

${ }^{3}$ El Pacto de Unidad nace en Santa Cruz en 2004, con el desafío de articular al movimiento campesino indígena del país e impulsar la realización de una Asamblea Constituyente «fundacional, soberana y participativa» que aprobara una Constitución fundada en el reconocimiento de la preexistencia de los pueblos y naciones originarias. Los estudiosos del tema coinciden en afirmar que «el Pacto de Unidad fue el espacio de imaginación y diseño del Estado Plurinacional» (Tapia, 2011). Fue la instancia que asumió la articulación del proyecto de un Estado Plurinacional en Bolivia en torno a las organizaciones campesinas-indígenas «que se configura como una especie de intelectual orgánico colectivo y que produce los dos documentos globales más importantes. Uno inicial, que está más marcado por los principios organizativos, y una segunda propuesta que ya contiene un diseño bajo la forma de Constitución» (Tapia, 2011). 
colectivos populares. Así, se inauguró un periodo de transformaciones discursivas y políticas profundas, con la redefinición del horizonte de los cambios deseables y posibles, que llegó a su máxima expresión en la nueva Carta Magna aprobada en 2009 con la revalorización de la comunidad, sus valores y principios de vida colectiva, en contraposición a los valores y principios del proyecto político liberal.

Nuevos referentes simbólicos de la comunidad política imaginada y los principios legitimadores de ciudadanía marcaron los primeros años del gobierno del MAS. Ser indígena y pertenecer a colectivos populares se consolidaron como pilares de la identidad boliviana. Ese proceso ocurrió a través de la introducción de un nuevo vocabulario en los discursos políticos y la normativa nacional, como el Vivir Bien, la Madre Tierra, el pluralismo político y económico, la comunidad y la solidaridad.

El escenario político también se transformó, con la inclusión de nuevos actores de ascendencia popular, campesina e indígena en los poderes ejecutivo, legislativo y judicial. Los impactos subjetivos de la revalorización política y simbólica de lo popular, indígena y campesino fueron intensos. Los sectores populares se sintieron reivindicados como individuos y colectividades en una sociedad estructurada por persistentes y profundos clivajes étnicos y de clase. La identificación con la historia personal de Evo Morales así como con las rupturas sociales que él y su gobierno llegaron a simbolizar, incluyendo la desnaturalización de prácticas y discursos discriminadores y excluyentes por parte de las elites criollas, fueron trascendentales.

A esta fuerza simbólica, encarnada físicamente por los nuevos representantes políticos, reforzada por los contenidos de los discursos oficiales y los nuevos espacios de interlocución con el Estado, se sumó la ascensión de una nueva clase media de origen popular e indígena, en un contexto 
excepcional de crecimiento económico, impulsado fuertemente por el alza de los precios internacionales de las materias primas y en específico de los hidrocarburos, minerales y alimentos. La inclusión social se fundó en la expansión de la capacidad de consumo de los estratos menos favorecidos.

Sin embargo, dicho proceso de inclusión simbólica, política y social se sustentó sobre bases económicas y políticas precarias que empezaron a agotarse con el fin del periodo de bonanza y de la disminución de recursos públicos que garantizaban el apoyo de grupos corporativos como la continuidad de las políticas redistributivas. La inclusión política de las clases populares siguió la lógica de distribución discrecional de recursos y favores por parte del gobierno a cambio de apoyo político. Proceso que fortaleció relaciones particularistas entre grupos corporativos y aquellos que toman decisiones, los resultados fueron la captura de políticas, programas y proyectos en lógicas no democráticas y la escalada de prebendas y de corrupción.

Silvia Rivera Cusicanqui (2012) expresa la reproducción de este tipo de gobernanza a lo largo de la historia de Bolivia:

No está por demás reiterar el nexo perverso que exhibe el gobierno de Evo Morales con el Estado colonial del MNR de los años 1950, que propició una escalada de corrupción y relaciones prebendales con dirigentes del campesinado indígena. Hoy, todo ello forma parte de una memoria estatal de colonialismo interno que ya no se circunscribe a un partido, siendo patrimonio de la clase política y del sistema de partidos en su conjunto. Así, todo alarde de ruptura del MAS con el viejo modelo político hace aguas al contemplar esta versión remozada de la parodia revolucionaria, tan bien expresada en sus políticas culturales y desarrollistas, que son una repetición, en clave de farsa, del adusto y racional programa de desarrollo del MNR. 
El contexto de bonanza económica favoreció la reedición de prácticas políticas clientelares y prebendales. Entre 2006 y 2014, el incremento de la capacidad de gasto corriente y de inversión pública fue exponencial en relación con el periodo anterior (1996 y 2005) y se sostuvo sobre la profundización de la dependencia del Estado respecto de las rentas de la explotación de recursos naturales. Para puntualizar, alrededor de 50 por ciento del presupuesto público fue generado por recursos provenientes de la exportación de hidrocarburos, minerales y agroindustria.

Asimismo, el buen desempeño macroeconómico en este lapso con un crecimiento promedio anual de 4.5 por ciento se explica tanto por la mejora de los términos de intercambio de las materias primas, como por una mayor demanda interna (capacidad de compra de la población), impulsada por los significativos incrementos en el gasto e inversión pública, que compensaron la contracción de la inversión extranjera directa (IED) y de la inversión privada nacional.

En consecuencia, hubo una disminución de la pobreza y la desigualdad. La inyección de recursos estatales en la economía ocurrió principalmente a través de obras públicas; compra de insumos de capital para empresas estatales; expansión del empleo en las entidades públicas; profundización de políticas redistributivas (en especial transferencias monetarias en forma de bonos); subsidios de gasolina, gas domiciliario y energía eléctrica; fondos de transferencia directa a las comunidades territoriales, como el Fondo de Desarrollo para los Pueblos Indígenas Originarios y Comunidades Campesinas (conocido como Fondo Indígena). ${ }^{4}$

${ }^{4}$ Este fondo se investiga por manejos discrecionales y corrupción con algunos líderes indígenas y campesinos presos. 
El incremento del salario mínimo nacional, el establecimiento de un techo en los sueldos de la administración pública y la implementación del doble aguinaldo, contribuyeron a profundos cambios en la dinámica del mercado de trabajo, por ejemplo, aumento del empleo menos calificado en servicios, comercio, construcción y transporte no vinculados con la producción y de baja productividad; disminución del desempleo; incremento de los ingresos reales de los trabajadores menos calificados; disminución de los ingresos reales de los trabajadores más calificados (Wanderley, 2015). Dinámicas que llevaron a los resultados sociales de signo positivo en el corto plazo como la disminución de la pobreza y la desigualdad. Sin embargo, con el fin de la bonanza, estos resultados están en riesgo.

En un contexto internacional de retracción de la demanda y de los precios internacionales de las materias primas, de reversión de las dinámicas socioeconómicas y de la intensificación de los conflictos sociales, resurgen interrogantes en cuanto al modelo efectivamente implementado a principios del siglo XXI y su sostenibilidad en el largo plazo. ¿Bolivia ha encauzado su trayectoria hacia el paradigma del Vivir Bien o ha profundizado el patrón de crecimiento extractivista bajo un nuevo capitalismo de Estado?

Con base en los análisis acerca de las políticas efectivamente implementadas y los resultados alcanzados en diez años, ${ }^{5}$ se constata que no obstante a los innovadores principios constitucionales y el conjunto de leyes aprobadas en concordancia con el paradigma de un desarrollo alternativo, dichas políticas propugnaron por la profundización del patrón extractivista. En realidad, la mayoría de las normativas referidas a los valores

${ }^{5}$ El análisis minucioso de las políticas públicas puede consultarse en Wanderley (2013). 
del Vivir Bien, al fortalecimiento de la economía social y comunitaria, a la promoción de la diversificación productiva y al respeto por el medio ambiente no se reglamentó ni se tradujo en políticas públicas coherentes e integrales; hasta la actualidad, el debate sobre otro desarrollo permanece marginal en la gestión de la política económica.

Todavía más revelador es la distribución del gasto e inversión pública. En un contexto excepcional de bonanza, el gobierno del MAS destinó la mayor parte de los recursos públicos a los rubros de hidrocarburos, minería y agronegocios, en desmedro de otros sectores económicos (agricultura familiar campesina, turismo e industria). Aunque el gasto y la inversión pública absoluta en cualquier sector se ha elevado en consonancia con el incremento de los ingresos públicos, en términos relativos la inversión pública se orientó a grandes proyectos en los sectores estratégicos principalmente hidrocarburífero y mineral. De ese modo, se reeditó el círculo vicioso: los ingresos estatales dependen en gran medida de los excedentes generados por las actividades extractivas y éstas se mantienen como destinatarias priorizadas del gasto e inversión públicos.

Tal orientación de las políticas económicas desencadenó o agudizó dinámicas económicas, laborales y sociales de difícil reversión. Tomando en cuenta que los principales yacimientos se encuentran en territorios comunitarios e indígenas, esta base de sustento del financiamiento público posee graves implicaciones sociales, políticas y económicas en las posibilidades de fortalecimiento de las otras economías (comunitarias indígenas) y en el respeto por la naturaleza, por lo tanto, son incompatibles con el paradigma del Vivir Bien.

De igual manera y considerando el bajo eslabonamiento del sector hidrocarburífero y minero, la priorización de la inversión aparte de no 
reforzar procesos de diversificación productiva, posee efectos negativos sobre los otros sectores económicos, en particular, en los generadores de empleo. Un ejemplo se observa en la producción nacional de alimentos, en la agricultura familiar de base campesina e indígena. Al no sobresalir en las políticas económicas, la producción nacional campesina no creció para responder al incremento de la demanda interna de productos de la canasta básica. Tampoco hubo incremento significativo de la productividad de la producción agrícola para el consumo interno, con excepción de algunos rubros (quinua, cacao y café) para exportación. Si anteriormente se tenía la capacidad de autoabastecimiento, como frutas y legumbres, en la actualidad su importación se ha elevado de manera considerable. Para tener una idea más clara, hoy se importa el triple de los alimentos respecto de hace diez años.

La insuficiencia de una estrategia efectiva que genere condiciones que sostengan los objetivos de seguridad con soberanía alimentaria se expresa en los exiguos recursos destinados a políticas y programas integrales dentro de un periodo de excepcional bonanza económica. ${ }^{6}$ Así expresa Urioste la visible contradicción entre el compromiso político y las políticas implementadas:

El actual Gobierno empezó su gestión en 2006 prometiendo una radical reforma agraria para eliminar el latifundio, promoviendo un modelo de base campesina, indígena, diversificado, con una producción que permita la seguridad y soberanía alimentaria. Pero estamos cada vez más lejos de eso. Hoy en Bolivia se importa el triple de alimentos que hace diez años. Lo que quiere

${ }^{6}$ Colque, Urioste y Eyzaguirre (2015) han efectuado un análisis reciente sobre la agricultura en Bolivia. 


\section{FERNANDA WANDERLEY}

decir que el aumento en el consumo que está viviendo la población boliviana no proviene de la producción local, sino de la importación de alimentos (entrevista con Iván Bustillos Zamorano, La Razón, 2015).

Esta situación también produce efectos negativos en la generación sostenida de empleo. En relación con el sector primario, principal reactivador de empleo, se constata la disminución de la ocupación en la agricultura y pecuaria debido a la migración campo-ciudad y a la reconversión de agricultores y productores rurales en comerciantes, transportistas, albañiles y mineros en trabajos informales. Dinámica impulsada por el incremento significativo de circulante (dinero) en la economía proveniente del alza de los precios internacionales de las materias primas exportadas por Bolivia. La caída de los precios del gas y de los minerales en los últimos años y consecuentemente la disminución de los ingresos por exportación, coloca en una encrucijada la sostenibilidad de los ingresos laborales de la mayoría de los trabajadores.

De modo paralelo, peligra la sostenibilidad de las políticas sociales. Además de que el gasto social se mantuvo dependiente de las rentas de los sectores extractivos se distribuyó a través de bonos monetarios, gasto corriente (salarios) y subsidios a servicios básicos (gas domiciliario, energía eléctrica y combustible), antes que el fortalecimiento de los sistemas institucionales de protección social (sistema público de salud, educación y seguridad social).

En conclusión, el objetivo de diversificación productiva y fortalecimiento de la economía social comunitaria fue marginal en las políticas efectivamente implementadas por el gobierno del MAS. La marginalidad de estos objetivos en las políticas económicas se comprueba incluso por 
la debilidad institucional del Ministerio de Desarrollo Productivo y Economía Plural (MDPyEP) — entidad que fortalece la institucionalidad de la economía plural y fomenta la agroindustria, producción de alimentos, artesanía, manufactura, industria y turismo. Tal ministerio no tuvo un papel protagónico en las políticas económicas, la opinión pública, las autoridades y los técnicos consideraron su actuación de «segunda línea»; en adición, estiman que su influencia en las decisiones económicas estratégicas fue escasa y sin mayores efectos en las políticas macro y microeconómicas de desarrollo productivo.

Dicha apreciación se manifiesta en los documentos oficiales del Ministerio de Desarrollo Productivo y Economía Plural, que reclama un mayor protagonismo político como coordinador entre diferentes ministerios e instancias (Ministerio de Planificación del Desarrollo, de Educación y su Viceministerio de Ciencia y Tecnología, a cargo de la creación del Sistema Boliviano de Innovación; Ministerio de Economía y Finanzas Públicas; Ministerio de Trabajo; Ministerio de Desarrollo Rural y Tierras; Banco de Desarrollo Productivo). Dicha función tampoco fue transferida a otro ministerio, de ahí que se ha observado una fragmentación y descoordinación entre los entes estatales centrales, y entre éstos y los subnacionales en la promoción de las políticas de desarrollo productivo en los sectores no tradicionales y fortalecimiento de la economía plural.

La novedad del modelo de desarrollo efectivamente implementado fue el mayor protagonismo del Estado en articulación con el sector privado empresarial, con base en la hipótesis de que la superación del lugar secundario del Estado durante el periodo neoliberal sería la condición suficiente para promover el desarrollo productivo del país. Esta idea desembocó en la ampliación de la economía estatal vía procesos de nacionalización y 
creación de empresas públicas, en un vasto espectro de sectores económicos. La economía social y comunitaria se relegó con relación a la economía pública y privada. Se asistió a la consolidación de alianzas políticas y económicas entre el gobierno del MAS y parte del empresariado tradicional (especialmente de los ámbitos financiero y agroindustrial) y de actores de la economía privada popular, en los sectores de servicios, transporte, comercio y minería, altamente dependientes de la bonanza económica.

Dos fueron las prioridades del modelo: mayor participación del Estado como agente directo en la economía mediante empresas públicas y redistribución de la riqueza por medio del aumento en el consumo social y el control de la inflación. Objetivos expresados en el Plan Sectorial de Desarrollo Productivo con Empleo Digno de 2006. En concordancia con el primer objetivo, las empresas públicas se convirtieron en el principal instrumento de política pública, además no se otorgó atención ni recursos al fomento — en paralelo_ — de un tejido productivo social y comunitario popular, a través de servicios y agencias de desarrollo, sistemas de innovación y asistencia técnica u otros. Respecto al segundo objetivo, se priorizó la regulación de precios y la importación de bienes de primera necesidad (alimentos), antes que la promoción de la producción nacional. Una consecuencia de lo anterior es el estancamiento de la productividad dentro del sector agrario campesino e indígena, el deterioro de la producción agrícola familiar y la creciente importación de productos de consumo.

La actuación de las empresas públicas (instrumento esencial de política pública) en los sectores no extractivos no propició el fortalecimiento de las organizaciones colectivas de productores. Se evidencia una tendencia a la relación contractual directa con productores individuales, debilitando a las asociaciones y la acción colectiva en el ámbito productivo. Asimismo, 
la relación vertical (de arriba hacia abajo) entre empresas públicas, productores individuales y asociaciones, debilitó las organizaciones colectivas referente al Estado (Quino, 2011; Ruesgas, 2013). El testimonio de un pequeño productor es elocuente:

El gobierno dice: «Sí les quiero apoyar a ustedes» y nos han matado a los cuatro, cinco meses que estábamos produciendo yogurt, queso, nos han matado con Lacteosbol (una de las empresas estatales creadas desde 2006). Además que ni siquiera son sostenibles. No terminan de destruir todo eso y se apartan, y esa población queda totalmente en ruina (representante del Movimiento de Economía Solidaria y Comercio Justo).

A largo plazo, el modelo establecido no trilló la ruta para la transformación del patrón extractivista en la Bolivia, es decir, no se implementaron políticas consistentes para transformaciones económicas estructurales en el marco de un proyecto de desarrollo alternativo con base en la pluralidad económica y la sostenibilidad ambiental. Por el contrario, se ha profundizado el extractivismo (hidrocarburos, minerales y agroindustria de monocultivos) en alianza con el sector privado transnacional y nacional, en menoscabo de la sostenibilidad ambiental, los derechos colectivos de los pueblos indígenas y la diversificación productiva nacional.

De frente al futuro se corrobora la continuidad de la apuesta por las actividades extractivistas en el tercer mandato del presidente Evo Morales. Los tres últimos decretos supremos (aprobados entre mayo y junio de 2015) ${ }^{7}$ dejan atrás las esperanzas sobre la gestación de un modelo de desarrollo

${ }^{7}$ Para ampliar la información, véase Agencia de Noticias Fides (13 de octubre de 2015). 
alternativo en Bolivia, en la medida que autorizan el ingreso de empresas petroleras a las 22 áreas protegidas del país, además de hacer retroceder el derecho de los pueblos indígenas a la consulta previa sobre proyectos en sus territorios. ${ }^{8}$ El presidente Evo Morales lo justificó en los siguientes términos: «Fundación que perjudique la explotación de los recursos naturales» en Bolivia «se tiene que ir del país», recordando que sufrirán el mismo destino que la cooperación danesa, expulsada por apoyar a los pueblos indígenas en la promoción de los derechos de la Madre Tierra. Aclaró también la medida: «No seremos guardabosques de los países industrializados». Explicó que las áreas forestales son una invención del «imperialismo norteamericano» (ANF, 2015).

\section{Inflexión del proceso de cambio y fragmentación de los movimientos sociales}

El proceso de cambio, que comenzó con rasgos de transformación épica en los niveles simbólico y político presentó problemas a partir de 2010. En 2011 ocurrió un conflicto entre el gobierno del MAS y los pueblos indígenas de tierras bajas por la construcción del tramo de la carretera que atraviesa el Territorio Indígena Parque Nacional Isiboro Sécure (TIPNIS), ubicado en los departamentos de Beni y Cochabamba, y jurisdicción de los pueblos Mojeno, Yuracaré y Chimán. Los pueblos indígenas denunciaron la vulneración de los principios constitucionales de la consulta previa, el

${ }^{8}$ En efecto, estas disposiciones desconocen el artículo 352 de la Constitución Política del Estado que establece la consulta libre, previa e informada, según las normas y procedimientos propios de las naciones y pueblos indígenas, y dan paso a contratos con empresas transnacionales a fin de explotar petróleo en esas áreas, sin reparar las resistencias indígenas o daños ambientales y sociales que puedan provocar las nuevas medidas. 
consentimiento libre e informado, la autonomía de los pueblos indígenas sobre su territorio y los impactos socioambientales negativos del megaproyecto. La intransigencia del gobierno a favor de la construcción de la carretera movilizó a la ciudadanía, que exigió coherencia con los compromisos políticos de transformaciones económicas estructurales.

Este conflicto evidenció los diferentes proyectos de desarrollo y las contradicciones de los intereses económicos de los actores sociales representados por el gobierno del MAS: por un lado, los intereses de los cocaleros, colonizadores, agroindustriales, empresarios del sector petrolero y minero, comerciantes, transportistas, cooperativistas mineros de ascendencia indígena; por otro, los derechos de los pueblos indígenas de tierras bajas y la defensa del medio ambiente. El TIPNIS entra a la historia como el evento que visibilizó las contradicciones entre dos proyectos económicos concurrentes en el partido gubernamental en los primeros años: $a$ ) la superación del modelo capitalista neoliberal y de base extractivista, a través del fortalecimiento de la economía social-comunitaria en el marco de la pluralidad económica y del Vivir Bien; b) el capitalismo de Estado fundado en la profundización del extractivismo (hidrocarburos, minerales y agroindustria), en alianza con empresarios internacionales y nacionales (tradicionales y de extracción popular). Al inicio del tercer mandato se puede afirmar que el segundo proyecto fue el vencedor.

Un resultado del conflicto fue la ruptura del Pacto de Unidad, tras la negativa de la Cidob y Conamaq de seguir respaldando al gobierno del MAS, y la redefinición del mapa político de los movimientos sociales con la formación de dos bloques: el primero con las organizaciones que están a favor del gobierno del MAS de modo incondicional y el segundo con las organizaciones que le retiraron su apoyo. 
Otro evento importante en el proceso de inflexión y que terminó en el enfrentamiento entre organizaciones sociales y económicas que luchan por el modelo de economía social y comunitaria, se suscitó a raíz de la elaboración de las normativas para su desarrollo, ${ }^{9}$ cuando se desencadenó una disputa sobre quién debería ser el interlocutor legítimo de la economía social-comunitaria frente al Estado en cuanto a la incidencia en la toma de decisiones y el acceso a recursos públicos, en particular los provenientes del Fondo Indígena. ${ }^{10}$

Las nuevas leyes establecieron dos conceptos de economía: «economía comunitaria», representada por federaciones y confederaciones político-territoriales; «economía social y solidaria», representada por centrales, plataformas y movimientos de asociaciones y cooperativas de productores. Es así que las normativas establecieron también dos tipos de actores sociales: Organizaciones Económicas Campesinas (Oeca) y Organizaciones Económicas Comunitarias (Oecom). Esta última categoría no existía antes de la Ley 144 de 2011.

La diferencia primordial entre ambos actores sociales, siguiendo la normativa, radica en el tipo de membresía de los socios que asumen la gestión de los emprendimientos colectivos. En las Oecom, la membresía es obligatoria por pertenencia a un territorio y la gestión es asumida por los gobiernos comunales. Esto significa que los socios de los emprendimientos económicos comunitarios son los habitantes de un territorio. En las Oeca, la membresía es voluntaria por afinidad de intereses entre personas

\footnotetext{
${ }^{9}$ Se alude en específico a la Ley 144 Revolución productiva comunitaria agropecuaria de 2011 y la Ley 338 Integración de la agricultura familiar y la soberanía alimentaria de 2013.

${ }^{10}$ Para más información correspondiente a los procesos de aprobación de estas leyes y su relación con las organizaciones sociales y económicas, véase Wanderley, Sostres y Farah (2015).
} 
que deciden formar asociaciones o cooperativas al interior de las comunidades territoriales o entre comunidades y la gestión la llevan a cabo los socios-trabajadores del emprendimiento.

La adscripción obligatoria territorial y la asociación voluntaria por afinidad constituyen diferentes principios de membresía y gestión colectiva. En las comunidades, en numerosas ocasiones, campesinos e indígenas están afiliados a ambas estructuras organizacionales y para ellos no existe ningún conflicto con mantener la doble membresía. Pese a que ambos tipos de organizaciones convivieron en los territorios rurales, los nuevos preceptos impulsaron disputas políticas en el país para ser elegidos como únicos representantes de la economía comunitaria. En realidad el conflicto tuvo lugar en la esfera de la política nacional alrededor de la adhesión o no al proyecto del partido oficial y su defensa incondicional: las Oecom con organizaciones sociales que alientan al partido en funciones de gobierno y las Oeca, que hasta ese momento habían mantenido un perfil político independiente.

De esta manera, la creación de la figura de las Oecom por la Ley 144 de 2011 pretendía expandir las funciones de los gobiernos comunales (denominados sindicatos agrarios territoriales) desde sus atribuciones sociales y políticas a funciones económicas como emprendimientos comunitarios. A pesar de la escasa experiencia organizativa en el ámbito económico, tales organizaciones fueron ascendidas como representantes legítimos de la economía social-comunitaria y, por lo tanto, se convirtieron en canalizadoras de los recursos dispuestos directamente para el fortalecimiento de la economía sociocomunitaria mediante fondos gestionados por ellas, mientras que las Oeca fueron excluidas.

Las organizaciones matrices de base territorial —la Confederación Sindical Única de Trabajadores Campesinos de Bolivia y la Federación 
Nacional de Mujeres Campesinas de Bolivia «Bartolina Sisa»—fueron reconocidas como las representantes únicas de la economía social-comunitaria. En tanto, las organizaciones matrices de la economía solidaria -el Movimiento de Economía Solidaria y Comercio Justo y la Coordinadora de Integración de Organizaciones Económicas Campesinas- siguieron peleando su inclusión desde sus espacios de representación. La contienda derivó en la aprobación de la Ley 338 de 2013 que las incluyó como otro actor económico de la economía comunitaria. Sin embargo, no se ha resuelto la pugna entre las organizaciones económicas colectivas por el reconocimiento del Estado.

A lo largo de diez años se observa que las organizaciones sociales y económicas populares concentraron sus esfuerzos en disputas sobre su participación legítima dentro del nuevo modelo de economía social y comunitaria con un manejo político del MAS y un dudoso compromiso con la diversificación productiva en un marco democrático, pluralista y sostenible ambientalmente.

\section{Conclusiones}

Varias preguntas surgen de la experiencia de los gobiernos progresistas en América Latina en los albores del siglo XXI. Es importante explicar las razones por las que los gobiernos que lograron canalizar una potente energía política gestada al interior de las sociedades contra el modelo económico hegemónico y a favor de modelos alternativos de desarrollo, se apartaron, en la práctica, de esos compromisos políticos. Aunado a ello, se caracterizaron por tensiones y contradicciones, entre cambios 
discursivos profundos y continuidades en la orientación de las políticas económicas.

En el caso boliviano, las normativas aprobadas no sólo guardan discordancias entre sí, además de que no fueron reglamentadas ni traducidas en políticas públicas. Debido a que las normativas agravaron conflictos y fragmentaciones al seno de las organizaciones sociales dificultaron la generación de acuerdos referentes a intereses compartidos, por encima de controversias bilaterales por favores y beneficios políticos. En efecto: pese al compromiso político con la superación del patrón extractivista a través de la diversificación productiva y el fortalecimiento de la economía plural de base popular, campesina e indígena en el marco de la armonía con la naturaleza, Bolivia siguió confiando en el patrón de acumulación fundado en actividades extractivas de recursos naturales no renovables, escasamente articuladas con aquellas que crean empleo, y dependientes de variables exógenas, proclives a tendencias cíclicas como el precio internacional de materias primas. Uno de los resultados del patrón de acumulación es la continuidad de la precariedad y marginalidad del empleo, más allá del aumento del ingreso de los trabajadores, en concreto de los menos calificados, en la última década. La mayoría de la población ocupada continúa generando sus propias fuentes de trabajo al margen de la seguridad social."

La experiencia reciente en la región obliga a que las reflexiones crítica, académica y política trasciendan el debate discursivo contra la ideología neoliberal y los ataques de la derecha. Es imperante redefinir las preguntas

${ }^{11}$ Si bien hay una tendencia al incremento de la cobertura de la seguridad social de corto y largo plazos en los últimos diez años, 65 por ciento del total de la población boliviana estaba excluida de la seguridad de corto plazo (salud) en 2010 y 71.46 por ciento de la población ocupada en 2011 no estaba afiliada a un fondo de pensiones (seguridad de largo plazo). 
y los marcos analíticos para explicar los procesos vividos, las relaciones entre el poder instituido y la sociedad civil, entre discurso y práctica política, y así ampliar la complejidad de los desafíos que enfrentan los horizontes de transformación ética y política hacia otra economía y otro desarrollo.

Al respecto, la pérdida creciente de legitimidad de los gobiernos progresistas en la región no puede interpretarse como el resultado del asalto de la derecha. Hoy vivimos una crisis de representación desde la izquierda, de ahí que sea el momento de ahondar en la reflexión crítica de los horizontes que guiaron prácticas y políticas de gobiernos que se mantuvieron en el poder por más de una década. La discusión abierta y plural de la historia reciente, sus avances y retrocesos, y la identificación de las contradicciones de los gobiernos progresistas permiten reconocer las profundas brechas entre las demandas y las expectativas gestadas al interior de las sociedades, así como las perspectivas políticas de la izquierda en el poder. Dicha inmersión hará factible delinear los desafíos de nuevos proyectos políticos progresistas.

Una de las lecciones fundamentales de las experiencias aludidas concierne a la incapacidad de la izquierda de comprender la gran novedad a inicios del siglo XXI: la insostenibilidad ambiental de un modelo de crecimiento ilimitado. Esta nueva realidad invalida el supuesto de la infinitud de los recursos naturales, el cual defiende modelos de pensamiento y de políticas de desarrollo que comparten derecha e izquierda. Es decir, el cambio climático, los desastres y desequilibrios ambientales y el agotamiento de los recursos naturales conforman las nuevas verdades que no fueron asumidas con seriedad en la gestión pública.

En contigua tesis, las experiencias recientes de gobiernos progresistas en América Latina reflejan la historia de inercias cognitivas y políticas que 
en la actualidad deben afrontar sus propios límites. Los gobiernos progresistas no abandonaron el modus operandi de gestión pública vertical, de arriba hacia abajo, y no se preocuparon por el fortalecimiento de espacios locales de deliberación democrática. Tampoco transformaron el modus pensanti de negación de la importancia de la diversificación productiva ambientalmente sostenible. Se afirma, entonces, que la apropiación política de visiones creativas (como Vivir Bien) cumplió un papel de legitimación política para líderes y tomadores de decisiones que no creían en ellas y por ende siguieron haciendo más de lo mismo: profundizar un patrón extractivista, comandado ahora por el Estado y, correlativamente, con la justificación del uso de las rentas para el combate a la pobreza.

Otra lección, que se relaciona estrechamente con la anterior, alude a la visión de inclusión social como disminución de la pobreza sin reducción significativa de la desigualdad. Ello condujo a políticas sociales dependientes del patrón extractivista, pautadas por la lógica de la acumulación irrestricta del capital en el mundo y la explotación ilimitada de los recursos naturales. Tal visión pretende justificar la profundización del extractivismo con el propósito de generar recursos suficientes para una relativa y coyuntural aminoración de la pobreza, sin alterar la vorágine de un capitalismo no regulado.

Es preciso, por tanto, efectuar una revisión crítica de la noción de inclusión social que pautó las estrategias de estos gobiernos y que se limitó a la ampliación de la capacidad de consumo a un costo ambiental insostenible. De modo semejante, es importante replantear qué se entiende por justicia social desde el paradigma del cuidado de los seres humanos y de la naturaleza con viabilidad económica. El desafío es pensar las transformaciones viables de construcción de justicia social (extinción de 
la pobreza, disminución de las desigualdades y nuevos patrones de consumo y estilos de vida) con equilibrio ambiental (reposición de los ciclos naturales y su preservación). Ambas dimensiones en igualdad de relevancia y, en consecuencia, fuera de la lógica secuencial — primero se explotan al máximo los recursos naturales para reducir la pobreza y después se intenta superar el extractivismo mediante la diversificación productiva. La lógica debe ser revertida a través de la articulación de políticas económicas de promoción de la diversificación productiva y de políticas sociales sostenibles. Tal proceso conduce a la discusión sostenida y abierta de la reforma fiscal progresiva y la asignación presupuestaria en un marco de deliberación con amplia participación ciudadana.

Una lección más se refiere a la gobernanza política, esto es, la relación Estado y sociedad en la gestión del poder. Estos gobiernos mantuvieron lógicas rentistas, extendieron prácticas clientelares y prebendales entre dirigencias sociales y políticas con manejos poco transparentes de los recursos públicos e institucionalizaron el uso discrecional de los fondos y la corrupción. Todo en nombre de la disminución de la pobreza en un contexto de bonanza económica excepcional. En el caso boliviano, dichas acciones han menoscabado la independencia organizativa de la sociedad civil con varios mecanismos de cooptación: reparto de cuotas de poder, oferta de empleos en el sector público, distribución de recursos y oportunidades de negocios a la sombra del Estado, al margen de la institucionalidad democrática y de procedimientos de rendición de cuentas.

Este modelo de gestión pública consolidó grupos de poder orientados a la defensa de intereses corporativos, en contra del bien común, a la vez que fomentó un modus operandi autoritario y violento en el seno de la sociedad civil. Es evidente además que en ese periodo se redujeron los 
espacios de discusión y deliberación de las políticas económicas que cimentaron el modelo económico implementado a escalas local y nacional; situación que ocurrió gracias a la reversión de la descentralización política y administrativa.

Con base en el análisis previo se plantean algunos desafíos que encaran los nuevos proyectos políticos progresistas. El gran reto radica en desarrollar un paradigma que traduzca los principios del Vivir Bien en políticas, programas y acciones por medio de la apertura de espacios de debate y deliberación; iniciativa que sin duda se encuentra en manos de la sociedad civil. Se trata de construir colectivamente trayectorias posibles de transformación económica con la articulación de tres principios: respeto por los ecosistemas, justicia social (superación de la pobreza y disminución significativa de la desigualdad) e inclusión del pluralismo (de actores sociales, organizaciones económicas y gobernanzas político-económicas) en un marco democrático.

Ello implica un cambio radical del paradigma del desarrollo, concepto con dos significados. El primero, de cambio histórico y procesos de transformación de las estructuras sociales, impulsado por fuerzas de índole variada y emergentes relaciones sociales, económicas, políticas y culturales. El segundo, de estrategias para direccionar los procesos económicos y sociales hacia determinados objetivos u horizontes políticos; estrategias que parten del rechazo del supuesto del crecimiento ilimitado asociado a la explotación irrestricta de la naturaleza y de la reproducción del patrón vigente de consumo de bienes materiales.

Constituye un cambio cognitivo profundo que trastoca el horizonte político progresista sobre la organización alternativa de la economía. El desarrollo económico, entendido como procesos de mejora sostenida 
de las condiciones de vida de poblaciones distintas insertas en ecosistemas disímiles (los cuales requieren cuidado para su continua reposición), replantea la forma de encarar los desafíos desde las dimensiones territorial y ecológica. Intervienen también: transición energética a fuentes renovables, limpias y bajas en niveles de carbono distinguiendo corto, mediano y largo plazos; innovación y desarrollo tecnológico para la diversificación productiva ecológicamente sostenible; uso consciente de recursos como el agua; procesos productivos limpios, eficientes y eficaces de bienes y servicios; gestión responsable de residuos y fortalecimiento de gobernanzas comunitarias-territoriales en contextos democráticos de deliberación y control social.

El nuevo paradigma impone una nueva escala de valores (métrica) para evaluar la contribución de las diferentes actividades económicas al desarrollo de las sociedades. Por lo tanto, la revisión crítica de los conceptos de eficiencia, eficacia y sostenibilidad financiera, en una perspectiva que no se limita a la dinámica mercantil y al principio de ganancias..$^{12}$ Los proyectos políticos alternativos requieren de otros indicadores (parámetros) de análisis de «costo y beneficio» de las actividades económicas, atendiendo a implicaciones y efectos medioambientales de la generación de excedente, de los resultados sociales (redistributivos) y de la calidad del empleo, tanto en territorios locales como de su impacto de derrame en la región, el país y el mundo. En otras palabras, nuevos criterios de evaluación de las actividades económicas para la transformación social-ecológica.

Con base en parámetros alternos puede comenzar la discusión sobre beneficios y costos del patrón extractivista a corto y largo plazos. Si por un

${ }^{12} \mathrm{Al}$ respecto, Tauile (2009), Gaiger (2008) y Coraggio (2008) abordan ese tópico. 
lado las ganancias económicas en periodos de bonanza crearon ingresos y políticas de reducción de la pobreza; por otro, establecieron la dependencia fiscal de los Estados, desestimularon otros sectores económicos y produjeron consecuencias medioambientales y sociales negativas y no sostenibles a largo plazo. Adicionalmente, se justifican propuestas de imposición tributaria a procedimientos económicos a fin de evitar la externalización de los impactos sociales y ambientales e incentivar las actividades o prácticas deseables.

La construcción de nuevos criterios de evaluación de beneficios y costos también hace plausible delinear la viabilidad de otros sectores económicos para sustituir las actividades extractivas y orientar la inversión pública y privada. Mientras no se superen las formas tradicionales de plantear el problema, no se conectarán adecuadamente economía, ecología y justicia social. En específico, es importante trascender la lógica de buscar sectores que sustituyan las rentas de los sectores extractivistas en el corto plazo. Se requiere identificar sectores, cadenas y emprendimientos que cumplan o tengan potencial para cumplir las exigencias ambientales, el aprovechamiento sostenible de los recursos, la contención de la contaminación, la articulación con otros actores y la generación de beneficios sociales y colectivos (empleo de calidad, redistribución justa de los excedentes, etcétera) desde una visión territorial.

Dentro de dicho escenario, las opciones estratégicas deben construirse en espacios democráticos de gestión pública. Los nuevos proyectos políticos progresistas tienen que comprometerse con seriedad con la necesidad de transformación real de la institucionalidad de la gestión del poder y de gestión pública. El punto de partida es el cuestionamiento de las relaciones clientelares y prebendales, de la apropiación privada de lo público, de 
las modalidades bilaterales de relación entre gobierno y grupos de interés de sociedad civil, y de las prácticas inequitativas (de género y otras) en todos los ámbitos sociales. Por tanto, se trata de cambiar las estructuras del sistema político y de la toma de decisión de política económica hacia un ámbito institucional efectivamente democrático.

En síntesis, debe ser un nuevo modelo de gestión orientado al fortalecimiento de la vida asociativa democrática en los territorios para que el conjunto de ciudadanos, actores sociales y económicos, puedan ser agentes activos en la búsqueda de soluciones colectivas a sus problemas y necesidades. Bajo el nuevo marco conceptual y de gestión, la preocupación central de las políticas económicas y sociales se vuelca en la construcción de capacidades institucionales democráticas y el fortalecimiento de sentidos compartidos de bien común y bien público por los actores sociales. Esto implica la articulación entre la consolidación de las capacidades democráticas de acción colectiva de los territorios y la promoción de espacios públicos e instituciones que faciliten la participación de organizaciones representativas para hallar soluciones a sus problemas y de control social del uso de recursos públicos y colectivos. ${ }^{13}$

Los nuevos proyectos políticos progresistas se comprometen con la inscripción de la economía en un entorno democrático a través del diseño de mecanismos efectivos de acceso a la información sobre las decisiones públicas y privadas, el destino de recursos, los gastos estatales y los resultados. En otras palabras, comprometidos con modelos de gobernanza democráticos en la toma de decisiones concernientes a las políticas económicas con amplia legitimidad social; propuesta central para enfrentar

${ }^{13}$ Acerca de este enfoque y las experiencias latinoamericanas, se recomienda consultar Bebbington, Delamaza y Villar (2005). 
problemas endémicos en la región: la corrupción y el uso discrecional de recursos públicos.

Desde esa visión, el horizonte político se amplía sustancialmente. Se trata de transformar las asimetrías de poder, de información y participación de los actores sociales en territorios con la construcción de nuevos entramados institucionales. La propuesta no pretende eliminar conflictos entre actores, sino generar espacios transparentes de diálogo y prácticas deliberativas para que gestionen sus diferencias y disputas, y lleguen a acuerdos que promuevan el desarrollo productivo.

En el nuevo paradigma, el fortalecimiento de los sistemas económicos debe estar al servicio del bienestar de la colectividad, en un marco democrático, de igualdad y respeto por la cultura local y la sostenibilidad ambiental. Esto implica, en términos más convencionales alterar las estructuras económicas a través de la diversificación productiva para crear empleos productivos y dignos. Sólo de esa manera es posible superar con sostenibilidad la pobreza y promover el ejercicio de derechos sociales — vivienda, educación, salud, acceso a servicios (agua, electricidad, saneamiento) y trabajo digno- con reglas y prácticas democráticas y gobernanzas locales plurales. La dimensión ecológica se enlaza con la dimensión económica debido al crecimiento de encadenamientos productivos sostenibles ambientalmente enmarcados en el ritmo normal de reposición de la naturaleza y en el manejo responsable de su apropiación, en el uso y destino de los residuos producidos por las actividades humanas. ${ }^{14}$

En este sentido, la propuesta de desarrollo económico alternativo entraña el fortalecimiento de tejidos socioeconómicos con base en las

${ }^{14}$ Para un análisis sobre las alternativas de transformación productiva ecológica, véase Gudynas (2015). 
potencialidades de los territorios y en el énfasis en las conectividades entre actores económicos, organizaciones e instituciones (ubicadas en las localidades y más allá de éstas). Por ello, el desafío reside en la promoción o expansión de la asociatividad y la cooperación horizontal y vertical entre unidades o emprendimientos económicos, en toda su pluralidad organizativa y jurídica, existentes o latentes en una localidad, así como en la innovación tecnológica y organizacional en armonía con la naturaleza. La apuesta se dirige a la función activa de actores-ciudadanos con identidades, modos de vida propios, saberes y prácticas, formas de relacionar y estrategias de vida plurales. Es decir, a la visibilidad y valorización del papel de la diversidad de actores económicos: empresas, emprendimientos sociales y solidarios, asociaciones, cooperativas, comunidades indígenas, unidades campesinas y domésticas, redes sociales y emprendimientos individuales y colectivos en el desarrollo económico y social de localidades, países y regiones.

\section{Referencias}

Agencia de Noticias Fides (ANF) (13 de octubre de 2015), «Evo: «Fundación que perjudique a la explotación de recursos naturales, se tiene que ir del país», Página Siete, en http://www.paginasiete.bo/economia/2015/6/18/evo-fundacionperjudique-explotacion-recursos-naturales-tiene-pais-60339.html

Albó, Xavier (1999), Raíces de América. El mundo aymara. Madrid, Alianza América/UNESCO.

Bebbington, Anthony, Gonzalo Delamaza y Rodrigo Villar (2005), «El desarrollo de base y los espacios públicos de concertación local en América Latina» 
(ponencia en la V Conferencia Latinoamericana de la International Society for Third-Sector Research, 10-12 de agosto), en http://www.lasociedadcivil. org/wp-content/uploads/2014/11/rodrigo_villar_gonzalo_de_la_maza_ anthony_bebbignton.pdf

Colque, Gonzalo, Miguel Urioste y José Luis Eyzaguirre (2015), Marginalización de la agricultura campesina e indígena, La Paz, Fundación Tierra.

Condori Laruta, Genaro (2003), «Experiencias comunicacionales de la Asociación de Radioemisoras Aymaras de La Paz», en Esteban Ticona (dir.), Los Andes desde los Andes: Aumaranaka, Qhichwanakana Yatxatawipa, Lup'iwipa, La Paz, Yachaywasi.

Coraggio, José Luis (2008), «La sostenibilidad de los emprendimientos de la economía social y solidaria», Otra Economía. Revista Latinoamericana de Economía Social y Solidaria, 2(3).

Gaiger, Luis Inácio (2008), «A dimensao emprendedora da economía solidaria: notas para un debate necessário», Otra Economía, 2(3).

Gudynas, Eduardo (2015), Extractivismos. Ecología, economía y política de un modo de entender el desarrollo y la naturaleza, Cochabamba, Centro de Documentación e Información Bolivia/Centro Latinoamericano de Estudios Superiores.

Moller, Edwin (1986), El cooperativismo como proceso de cambio. De la comunidad tradicional a la cooperativa moderna, La Paz, Los Amigos del Libro.

Programa de las Naciones Unidas para el Desarrollo (PNUD) (2016), Informe Regional sobre Desarrollo Humano para América Latina y el Caribe 2016, Naciones Unidas.

Quino Mamani, Eliseo Manuel (2011), «Evaluación del Decreto Supremo 0225 — Creación de la Empresa Boliviana de la Almendra y Derivados-, como política pública para la Amazonia de Bolivia, y de sus efectos entre los actores 


\section{FERNANDA WANDERLEY}

primarios de la cadena productiva de la castaña» (tesis de maestría), La Paz, Universidad Mayor de San Andrés/Centro de Investigación para el Desarro1lo Sustentable.

Rivera Cusicanqui, Silvia, Ramón Conde y Felipe Santos (1992), Ayllus y proyectos de desarrollo en el norte de Potosí, La Paz, Aruwiyiri/THOA.

Rivera Cusicanqui, Silvia (2012), «Del MNR a Evo Morales: disyunciones del Estado colonial», en http://www.bolpress.com/art.php?Cod=2012123104

Ruesgas Requena, Gabriela (2015), «EMAPA y el modelo de agricultura por contrato en la producción de trigo: dos estudios de caso en Cochabamba y Tarija» (tesis de maestría), La Paz, Universidad Mayor de San Andrés/Centro de Investigación para el Desarrollo Sustentable.

Tapia Mealla, Luis (2011), «Consideraciones sobre el Estado Plurinacional», en Descolonización en Bolivia. Cuatro ejes para comprender el cambio, La Paz, Vicepresidencia del Estado Plurinacional de Bolivia/Fundación Boliviana para la Democracia Multipartidaria.

Tauile, José Ricardo (2009), «Economía solidaria y autogestao: creaçao e recreaçao de trabajo e renda», en Marcelo Paixao y Castelo Braco (orgs.), Trabajo, autogestao e desenvolvimento: escritos escolhidos 1981-2005, Rio de Janeiro, Editora UFRJ.

Wanderley, Fernanda, Ivonne Farah y Fernanda Sostres (2015), La economía solidaria en la economía plural: discursos, prácticas y resultados en Bolivia. La Paz, Universidad Mayor de San Andrés/Centro de Investigación para el Desarrollo Sustentable/Hegoa/Plural Editores, en https://cides.academia.edu/ FernandaWanderley

Wanderley, Fernanda (2013), ¿Qué pasó con el proceso de cambio en Bolivia? Ideales acertados, medios equivocados y resultados trastocados, La Paz, Universidad 


\section{ENTRE EL EXTRACTIVISMO Y EL VIVIR BIEN}

Mayor de San Andrés/Centro de Investigación para el Desarrollo Sustentable, en https://cides.academia.edu/FernandaWanderley (2015), «¿Qué cambió en el mercado de trabajo para hombres y mujeres en Bolivia? (2001-2011)», Umbrales (27/28). 